\title{
Critical evaluation of two approaches to achieve universal health coverage in India
}

\author{
Shyamkumar Sriram* \\ Department of Health Services Policy and Management, University of South Carolina, Columbia, South Carolina,
} USA

Received: 02 June 2018

Accepted: 05 July 2018

\section{*Correspondence:}

Dr. Shyamkumar Sriram,

E-mail: shyam.silverhawk@gmail.com

Copyright: (C) the author(s), publisher and licensee Medip Academy. This is an open-access article distributed under the terms of the Creative Commons Attribution Non-Commercial License, which permits unrestricted non-commercial use, distribution, and reproduction in any medium, provided the original work is properly cited.

\begin{abstract}
The WHO report on the path to Universal Health Coverage (UHC) emphasizes that every person should receive the necessary healthcare without enduring financial hardship at the time of getting care. United Nations' Sustainable Development agenda incorporates one goal (Goal 3) that is related to health and well-being of the population and one of the specific targets of the goal is to improve financial risk protection through the achievement of universal health coverage. More than 100 countries in the world have either started their reforms towards UHC or have already achieved it and India is one of the countries trying to achieve UHC. Out of the 1.324 billion people in India, only $11 \%$ of the population has any form of health insurance coverage. Around, $42 \%$ of India's population is Below Poverty Line (BPL). Rashtriya Swasthya Bima Yojana is a health insurance program started in 2007 that provides a wide range of healthcare services for BPL families. Rajiv Aarogyasri Community Health Insurance is a state health insurance program started in Andhra Pradesh as one of the first programs in India to provide health insurance to poor people. In India, 39 million people are being impoverished due to OOP health expenditures each year, and a quarter of these expenditures are contributed by hospitalization Out-of-pocket expenditures even after the financial protection provided by a number of health insurance programs. This review will critically evaluate the two health insurance approaches which aim to achieve UHC in India by providing health protection to the indigent.
\end{abstract}

Keywords: Universal health coverage, Rashtriya Swasthya Bima Yojana, Rajiv Aarogyasri Community Health Insurance

\section{INTRODUCTION}

The World Health Report 2010 mentions that a health system providing Universal Health Coverage (UHC) should provide access to the necessary health services to all people needing them with good quality and without financial hardship. ${ }^{1}$ UHC consists of 5 important aspects, namely access to healthcare, coverage, package of services, financial risk protection and rights-based approach. $^{2}$ The main components of UHC are quality and coverage. Coverage will comprise of service coverage and financial coverage. ${ }^{3}$ The three dimensions of UHC are the population covered; services covered and costs covered, as represented in Figure 1, reproduced from the WHO report (2015). ${ }^{3}$

Out-of-pocket (OOP) payments need to be eliminated if UHC is to be achieved. ${ }^{4}$ The mechanism to eliminate OOP expenses is by providing health insurance. Increasing insurance coverage is associated with an increase in healthcare coverage and financial protection which improves the health status of the population. ${ }^{5}$ The WHO Health System Framework defines four overall goals of any health system, namely improved health, responsiveness, social and financial risk protection, and improved efficiency. ${ }^{6}$ 


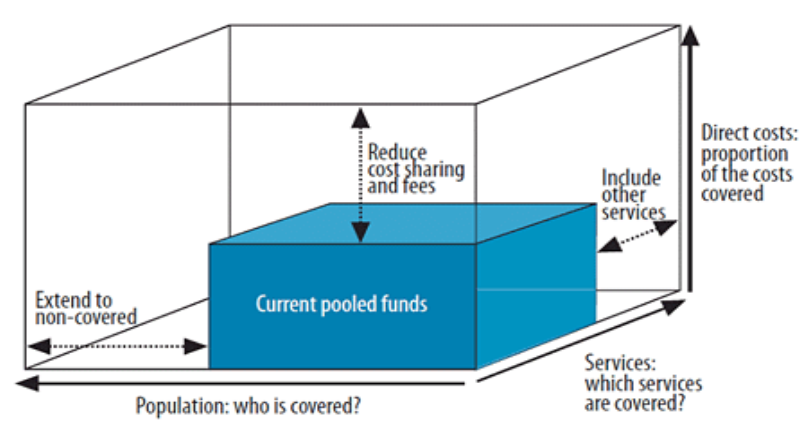

Figure 1: Three dimensions of universal health coverage.

\section{Objective}

The objective of this paper is to critically evaluate two of the approaches to achieving UHC in India. The approaches chosen for evaluation in this paper are two insurance programs, which have taken an important step towards UHC in India. The paper will use the various dimensions of UHC to critically evaluate the success, progress and acceptability of these two approaches towards UHC. The paper hypothesizes that the approaches have not achieved UHC in India. This hypothesis is tested by researching relevant literature to assess whether these two approaches have achieved UHC.

\section{INDICATORS FOR UNIVERSAL HEALTH COVERAGE}

Coverage indicators include both services coverage and financial coverage. Indicators for preventive service coverage include family planning, antenatal, skilled birth attendance, DPT3 immunization coverage, and percentage of the population using improved drinking water sources and sanitation. ${ }^{3}$ The financial coverage indicator is the number of people spending $40 \%$ or more of their capacity to pay on OOP ${ }^{7,8}$ In India, there is no national data available on quality indicators such as patient safety, effectiveness, and people-centeredness. ${ }^{3}$

\section{SITUATIONAL ANALYSIS OF INDIA'S HEALTH SYSTEM}

India has a very low public health spending with only $0.94 \%$ of the GDP. ${ }^{9}$ The government contribution of the total health spending is only $22 \%$ with $78 \%$ of private health spending. ${ }^{9}$ Every year around 39 million people are impoverished because of catastrophic health expenditure. ${ }^{10} 74 \%$ of OOP spending was on outpatient care and only $26 \%$ on inpatient care. ${ }^{11}$ Public health care in India is free of cost in most cases or charges a minimal service charge. ${ }^{11}$ However, the quality of services in the public health system is very poor, and people are unsatisfied. $^{12,32} \mathrm{~A}$ majority of the people used private health services for their health care needs. ${ }^{12}$ Around 20\%$28 \%$ of diseases in India are untreated because of the lack of financial protection. ${ }^{12}$ Around $30 \%-47 \%$ of inpatient care in India was financed by the sale of property and loans. $^{12}$ There are difficulties in the expansion of insurance coverage in India because only $7 \%$ of the workforce is in the organized sector. ${ }^{13}$

\section{UNIVERSAL HEALTH COVERAGE IN INDIA}

India does not currently have UHC. ${ }^{10}$. The $12^{\text {th }}$ five-year plan (2012-17) of the Government of India (GOI) tries to achieve UHC. ${ }^{10}$ GOI created a High Level Expert Group (HLEG) in 2010, which prepared a report for the achievement of UHC in India by $2022 .{ }^{14}$ The health insurance system in India is only rudimentary and available to only few groups of advantaged individuals. ${ }^{15-}$ 18 In India, the unmet need for healthcare is very high with the people having the highest need having the least access to health care. ${ }^{19-22}$ In India, the IMR among the poorest wealth quintile is around 82 per 1000 live births, while the IMR among the richest quintile is only 34 per 1000 live births. ${ }^{23}$ Women in the richest quintile are more than six times more likely to have an institutional delivery compared to poorer women. ${ }^{24}$ These statistics show there are wide disparities between the rich and poor in access to healthcare. The approaches to achieve UHC in India currently target poor people.

\section{RASHTRIYA SWASTHYA BIMA YOJANA (RSBY)}

\section{Access}

Around $42 \%$ of India's population is below poverty line (BPL). ${ }^{25}$ RSBY is a health insurance program governed by the Ministry of Labor and Employment of GOI providing a wide range of services for BPL families. ${ }^{11}$ Access to in-patient services is available to all people who are BPL and are registered and provided with the RSBY card. $^{26}$ This program has been extended to cover a number of informal sector workers having problems paying for care. ${ }^{26}$ People can take their RSBY smart card to any hospital from the list of empanelled hospitals and avail the services. $^{26}$ The RSBY smart card has identification information for each person which prevents misuse. Using a centralized database connecting all the empanelled hospitals, data is collected, analyzed and monitored, assuring quality control. ${ }^{26}$

\section{Coverage}

The Package of services covered by RSBY includes the In-Patient (IP) services which require hospitalization of at least one day. ${ }^{26}$ No Out-Patient (OP) services are covered. RSBY covers people of all ages, and there are no exclusions based on pre-existing conditions. ${ }^{26}$ RSBY covers five members of the insured family. ${ }^{26}$ The insurance provides coverage benefits of Rs.30,000 per family for diseases which require hospitalization. ${ }^{26}$ The premium is paid by the government of India and IP care is almost free to the patient. ${ }^{26}$ This shows that there is 
fairness of financial contributions and financial protection for getting health care for poor people.

\section{Critical evaluation of RSBY}

Access is not available to around $50 \%$ of the eligible people for the program because they are currently not enrolled in RSBY due to the lack of availability of full lists of the eligible participants, higher cost of enrolment, and high migration rates. ${ }^{27}$ Beneficiary knowledge about the covered services under RSBY is also limited. ${ }^{26}$ There is no awareness creation component of the program. There also has been denial of treatment to smart card holders because of disputes between the hospital and the insurer, for there are no proper mechanisms to resolve. ${ }^{26}$ The rate of reimbursements for many of the procedures are also very low. ${ }^{26}$ Evaluations have shown that poor people are facing a number of problems with RSBY in the areas of enrolment, access and coverage. ${ }^{26}$

In India, OP services are the reason for $75 \%$ of OOP expenditure. $^{11}$ RSBY covers only a specific set of services such as IP and emergency services and does not cover OP and drugs which contribute a major portion of OOP expenditures. ${ }^{11}$ Further, no preventive care services were covered. ${ }^{28}$ This shows that RSBY is not responsive to the needs of patients. RSBY leads to misuse of services, since both the physician and the patient have the incentive to convert an OP case into an IP admission, leading to unwanted increased utilization. ${ }^{26}$ This program targets only poor people and does not offer UHC. ${ }^{11}$

Evidence shows that there are serious coverage gaps in the RSBY. The financial protection provided by RSBY is not comprehensive since many OP services are not covered, and also IP services have a coverage limit of Rs.30,000 per family per year, which is very low according to the current hospitalization expenses in India. India is facing an epidemiological transition, and there is an increasing burden of non-communicable diseases, the treatment of which does not require IP admissions. ${ }^{26}$ There are many instances of significant delay in access to health services among the poor in hospitals, and RSBY does not adequately address this equity issue. ${ }^{26}$ These show that although RSBY increases access and coverage to poor people, still they do not provide UHC.

\section{RAJIV AAROGYASRI COMMUNITY HEALTH INSURANCE (AAROGYASRI)}

\section{Access}

The Government of Andhra Pradesh, a state in India, started the Aarogyasri program in 2007, to provide coverage for treatment for serious conditions to BPL population in the state. ${ }^{29}$ The scheme was completely state-funded with minimal premium contributions from the people. ${ }^{29} 80 \%$ of the BPL populations in Andhra Pradesh have BPL ration cards, and they are eligible to use the health services under this scheme. ${ }^{30}$ The objective of the program is to provide access to tertiary care services, IP services, protection from catastrophic health expenditures and UHC for poor people in the state of Andhra Pradesh. ${ }^{31}$ Aarogyasri uses the public-private partnership (PPP) model of providing access to care. ${ }^{30}$

\section{Coverage}

938 tertiary care procedures are covered under Aarogyasri. ${ }^{28}$ The families are provided a coverage for Rs.200,000 per family per year, and there are no restrictions on the number of family members to be enrolled in Aarogyasri. ${ }^{29}$ People avail the covered services from a range of empanelled providers both public and private. ${ }^{30}$ State government pays the entire premium for the insurance. ${ }^{30}$ Aarogyasri includes people of all ages and there is no exclusion based on pre-existing conditions. ${ }^{30}$ Aarogyasri provides financial protection for poor people. ${ }^{30}$ Aarogyasri also provides coverage to people in the informal sector. ${ }^{30}$ Government pays the whole premium, so there is no burden on poor people in this program.

\section{Critical evaluation of AAROGYASRI}

The number of people treated for various conditions has improved greatly after the introduction of Aarogyasri. ${ }^{30}$ But still $20 \%$ of the eligible population is not included. ${ }^{30}$ The empaneled doctors discharge patients earlier than the normal required recovery time, which may be due to issues with the payment mechanism. ${ }^{30}$ Violations of program regulations, such as provision of excessive treatment and surgeries, collection of user-fees and lack of provision of essential medicines, have been recorded. ${ }^{30}$ This shows that there is poor quality control and regulatory mechanisms in place.

Aarogyasri is more focused on provision of tertiary care, although the majority of the communicable and noncommunicable diseases could be treated as OP. ${ }^{30}$ Although Aarogyasri has improved access, it does not help in strengthening the primary health infrastructure which is vital to achieving UHC. The main cause of mortality and morbidity among the poor in India is the lack of primary health care. ${ }^{30}$ After the introduction of Aarogyasri, there has been a trend for patients to use the tertiary services of corporate hospitals rather than government hospitals, thus further weakening the public health infrastructure in India. ${ }^{30}$

The PPP model followed by Aarogyasri is not benefiting the public health infrastructure. ${ }^{30}$ and hinders achievement of the National Public Health Goal to strengthen the government health infrastructure which is laid by the National Rural Health Mission. ${ }^{30}$ The National Commission on Macroeconomics and Health observed that the health insurance programs that buy services from the private sector will not improve the health status of the people. $^{32}$ 


\section{CONCLUSION}

The HLEG report on UHC recommends that UHC in India could only be achieved if the primary health care facilities receive a minimum of $70 \%$ of health spending, public spending on the purchase of medicines increase from $0.1 \%$ to $0.5 \%$ GDP, and all the health facilities in India are upgraded to match the Indian Public Health Standards. ${ }^{33}$ The health insurance programs currently available in India do not help in achieving these recommendations and only strengthen the private health infrastructure which mainly targets rich people. There are problems in sustainability of the health insurance programs because the mechanisms for financing the health system such as strong collecting systems are lacking in India. $^{34}$ Thus, new innovative financing mechanisms should be identified to make the insurance system sustainable.

In order to achieve UHC, an insurance covering a wide range of services, price control of essential drugs, effective governance, adequate quality control, patient protection and information transparency mechanisms are needed. ${ }^{11,33,35-37}$ It is vital to provide financial protection to all the citizens of India and not only to poor people. Currently Aarogyasri and RSBY do not cover preventive and OP services. None of the UHC preventive and OP service coverage indicators are achieved by either insurance program, but IP coverage is increased and the financial coverage indicators are achieved by both for poor people. Non-financial barriers such as lack of education, information, location of health facilities and trust in the provider are important to improve access and these are not addressed by available health insurance programs. $^{29}$

\section{Funding: No funding sources}

Conflict of interest: None declared

Ethical approval: Not required

\section{REFERENCES}

1. The World Health Report 2010: Health Systems Financing: The Path to Universal Coverage. Geneva: WHO 2010. Available at: www.who.int/whr/2010/en/. Accessed 05 March 2017.

2. Stuckler D, Feigl AB, Basu S, McKee M. The political economy of universal health coverage (background paper for the First Global Symposium on Health Systems Research). Geneva: WHO.2010. Available at: www.pacifichealthsummit.org/ downloads/UHC/the\%20political\%20economy $\% 20$ of\%20uhc.PDF. Accessed 07 March 2017.

3. Joint WHO/World Bank Group Report. Tracking Universal Health Coverage. First Global Monitoring Report. WHO. 2015. Available at: http://apps.who.int/iris/bitstream/10665/174536/1/9 789241564977_eng.pdf. Accessed 07 March 2017.
4. World Health Organization. Health in 2015: from MDGs to SDGs. Chapter 3: Universal Health Coverage. Geneva: WHO. 2015. Available at: http://apps.who.int/iris/bitstream/10665/200009/1/9 789241565110_eng.pdf?ua=1. Accessed 05 March 2017.

5. Moreno-Serra R, Smith PC. Does progress towards universal health coverage improve population health? Lancet. 2012;380(9845):917-23.

6. World Health Organization. Strengthening health systems to improve health outcomes. WHO's Framework for Action. WHO.2007. Available at:http://www.who.int/healthsystems/strategy/every bodys_business.pdf. Accessed 10 March 2017.

7. Xu L, Evans D, Kawabata K, Zeramdini R, Klavus J, Murray C. Households catastrophic health expenditure: a multi-country analysis. Lancet. 2003;362(9378):111-7.

8. Onoka CA, Onwujekwe OE, Hanson K, Uzochukwu BS. Examining catastrophic health expenditures at variable thresholds using household consumption expenditure diaries: Catastrophic health expenditure in Nigeria. Trop Med Int Health. 2011;16(10):133441.

9. MoHFW, Government of India. National health accounts of India 2004-05, national health accounts cell. New Delhi: Ministry of Health and Family Welfare, Government of India, 2009. Available at: http://planningcommission.nic.in/reports/genrep/hea 1th/National_Health_Account_04_05. Accessed 12 March 2017.

10. Press Information Bureau, Government of India. Available at: http://pib.nic.in/newsite/erelease. aspx?relid=88129. Accessed 14 March 2017.

11. Kumar AKS, Chen LC, Choudhury M, Ganju S, Mahajan V, Sinha A, et al. Financing health care for all: challenges and opportunities. Lancet. 2011;377(9766):668-79.

12. Ministry of Health and Family Welfare, Government of India. Select health parameters: a comparative analysis across the National Sample Survey Organization 42nd, 52nd, and 60th Rounds. 2007. Available at: http://www.whoindia.org/ LinkFiles/Health_Finance_NSSO_Report.pdf.

Accessed on 15 March 2017.

13. National Commission for Enterprises in the Unorganised Sector. Report on the conditions of work and promotion of livelihoods in the unorganised sector. August, 2007. Available at: http://nceus.gov.in/Condition_of_workers_sep_2007 .pdf. Accessed 15 March 2017.

14. Singh Z. Universal Health Coverage for India by 2022: A Utopia or Reality? Indian J Community Med. 2013;38(2):70-3.

15. Gupta I, Trivedi M. Health insurance: beyond a piecemeal approach. Econ Polit Wkly. 2006;41:2525-8.

16. Acharya A, Ranson K. Health care financing for the poor: community-based health insurance schemes in Gujarat. Econ Polit Wkly. 2005;40:4141-50. 
17. Ellis RP, Alam M, Gupta I. Health insurance in India: prognosis and prospects. Econ Polit Wkly. 2000;35:207-17.

18. Ranson MK, Sinha T, Chatterjee M, Acharya A, Bhavsar A, Morris SS, et al. Making health insurance work for the poor: learning from SEWA's community-based health insurance scheme. Soc Sci Med. 2006;62(3):707-20.

19. Hart JT. Three decades of the inverse care law. BMJ. 2000;320(7226):18-9.

20. Sen G, Iyer A, George A. Structural reforms and health equity: a comparison of NSS surveys, 198687 and 1995-96. Econ Polit Wkly. 2002;37:134252.

21. Singh $\mathrm{CH}$, Ladusingh L. Correlates of inpatient healthcare seeking behavior in India. Indian J Public Health 2009;53:6-12.

22. Gaudin S, Yazbeck AS. Immunization in India 1993-1999: Wealth, Gender, and Regional Inequalities Revisited. Soc Sci Med. 2006;62(3):694-706.

23. National Family Health Survey (NFHS-3), 2005-06: India. International Institute for Population Sciences (IIPS) and Macro International. 2007. Available at: http://www.measuredhs.com/aboutsurveys/search/m etadata.cfm?surv_id=264\&ctry_id=57\&SrvyTp. Accessed 16 March 2017.

24. Balarajan Y, Selvaraj S, Subramanian SV. Health care and equity in India. Lancet 2011;377(9764):505-15.

25. Chen S, Ravallion M. The developing world is poorer than we thought, but no less successful in the fight against poverty. World Bank Policy Research Working Paper Series 4703. Washington DC: World Bank, 2008.

26. Taneja PK, Taneja S. Rashtriya Swasthya Bima Yojana (RSBY) for Universal Health Coverage Asian Journal of Management Cases 2016;13(2):108-24.

27. $\mathrm{Wu} \mathrm{Q}$. What cause the low enrolment rate and utilization of Rashtriya Swasthya Bima Yojana: A qualitative study in two poor communities in India. Liverpool: Liverpool School Trop Med. 2012.
28. Vilcu I, Probst L, Dorjsuren B, Mathauer I. Subsidized health insurance coverage of people in the informal sector and vulnerable population groups: trends in institutional design in Asia. Int J Equity Health. 2016;15:165.

29. Narasimhan H, Boddu V, Singh P, Katyal A, Bergkvist S, Rao M. Access to the Rajiv Aarogyasri community health insurance scheme of Andhra Pradesh. Health, Culture and Society. 2014;6(1):8597.

30. Reddy S. Aarogyasri Scheme in Andhra Pradesh, India: Some Critical Reflections. Social Change 2013;43(2):245-61.

31. Rao M, Ramachandra SS, Bandyopadhyay S, Chandran A, Shidhaye R, Tamisettynarayana S, et al. Addressing the healthcare needs of people living below the poverty line: A rapid assessment of the Andhra Pradesh Health Insurance Scheme. Natl Med J India. 2011;24(6):335-41.

32. Government of India. Report of the national commission on macroeconomics and health. New Delhi: National Commission on Macroeconomics and Health, Ministry of Health and Family Welfare 2005.

33. High level expert group report on universal health coverage for India. Instituted by the Planning Commission of India. 2011.

34. Tsounta E. Universal health care 101: lessons for the eastern Caribbean and beyond. Washington DC: Internal Monetary Fund, 2009.

35. Bloom G, Kanjilal B, Peters DH. Regulating health care markets in China and India. Health Aff (Millwood). 2008;27(4):952-63.

36. Peters DH, Muraleedharan VR. Regulating India's health services: to what end? what future? Soc Sci Med. 2008;66(10):2133-44.

37. Dror D. Health insurance and the poor: myths and realities. Econ Polit Wkly. 2006;41:4541-4.

Cite this article as: Sriram S. Critical evaluation of two approaches to achieve universal health coverage in India. Int J Community Med Public Health 2018;5:3159-63. 